\title{
Changes in skeletal muscle cellularity in starved and refed young rats*
}

\author{
BY P. V. J. HEGARTY AND K. O. KIM \\ Department of Food Science and Nutrition, University of Minnesota, \\ St Paul, Minnesota 55108, USA
}

(Received 3I May I979-Accepted I7 March I980)

\begin{abstract}
I. All food was withdrawn from male weanling rats until a $40 \%$ loss of body-weight was attained. Another group of animals was treated similarly and then refed a stock diet until the original body-weight was attained.

2. The body-weight loss caused a significant reduction in the weight of the heart, kidney, liver and epididymal fat pads. Refeeding produced a return to the control weight of the heart and kidney, an increase in the weight of the liver and a deficit in the weight of the epididymal fat pads.

3. Body-weight loss caused a decrease in the weight of the three different muscles studied, and in the number and diameter of the fibres in each muscle. Refeeding restored the weight and cellularity of two of the three muscles to that of the control animals. The soleus muscle was heavier in the refed animals when compared to controls due to an increased fibre diameter.

4. It is concluded that the decrease in the number and diameter of muscle fibres during starvation in the rat can be restored on refeeding a stock diet.
\end{abstract}

A restriction in food intake causes a reduction in growth rate which produces a decrease in the transverse dimensions of skeletal muscle fibres in humans (Cheek et al. 1970; Alleyne et al. 1977; Hansen-Smith et al. 1979), young rats (Hill et al. 1970; McCarter et al. 1978) and pigs (Stickland $e t$ al. 1975). The effects of severe restrictions of food intake, producing a loss of body-weight, on the number and size of skeletal muscle fibres have been studied less extensively. Goldspink (1965) and Rowe (1968) reported a decrease in diameter but no change in the number of fibres when muscle weight of mice was reduced due to severe food restrictions. However, Layman (1978) reported a reduction in both fibre number and fibre diameter in muscles from rats deprived of all food.A recent study in our laboratory examined three muscles (soleus, plantaris and biceps brachii) in young rats, rabbits, guinea-pigs and hamsters who underwent a $35-45 \%$ loss in body-weight due to a total withdrawal of food (Kim \& Hegarty, 1978). A decrease in muscle fibre number due to starvation was observed in all three muscles from the rat and in the biceps brachii muscle from the hamster. Starvation produced no decrease in the number of fibres in any of the muscles from the rabbit or the guinea-pig.

Montgomery (1962) and Krishnamurthy et al. (1971) presented histological evidence of a loss of muscle fibres in undernourished children. Rehabilitation of skeletal muscle is not complete at the time of clinical recovery of previously undernourished children (Krishnamurthy et al. I97 ; Hansen-Smith et al. 1979). Therefore, the response of muscle fibres to a total starvation and subsequent recovery when rats were fed on an adequate diet was studied in the present investigation. The number and diameter of fibres were simultaneously measured as an index of cellularity changes in different muscles. The use of DNA to extrapolate cell number and cell size was not considered because of difficulties in interpretation of cell number from DNA measurements (Sands et al. 1979; Layman et al. 1980).

\footnotetext{
* Scientific Journal Series paper no. I0808, Minnesota Agricultural Experiment Station.
} 
Table I. Body-weights $(g)$ and weights $(m g)$ of organs and epididymal fat pads in control, starved and refed rats

(Mean values with their standard errors)

\begin{tabular}{|c|c|c|c|c|c|c|c|c|c|c|}
\hline \multirow[b]{2}{*}{ Treatment } & \multirow[b]{2}{*}{ No. of animals } & \multirow{2}{*}{$\overbrace{\text { Mean SE }}^{\begin{array}{c}\text { Total } \\
\text { body-wt }\end{array}}$} & \multirow{2}{*}{$\overbrace{\text { Mean SE }}^{\begin{array}{c}\text { Empty- } \\
\text { body-wt }\end{array}}$} & \multicolumn{2}{|c|}{ Heart } & \multicolumn{2}{|c|}{ Kidney } & \multicolumn{2}{|c|}{ Liver } & $\begin{array}{l}\text { Epididymal } \\
\text { fat pads }\end{array}$ \\
\hline & & & & Mean & $\mathrm{SE}$ & Mean & SE & Mean & SE & Mean SE \\
\hline Control & 4 & $\begin{array}{ll}68.6 & 0.9\end{array}$ & $57.4 \quad 0.5$ & 293.5 & 7.9 & $471 \cdot 7$ & $14 \cdot 2$ & 4418 & 156.6 & $185.5 \quad 16.7$ \\
\hline & & **** & 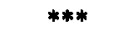 & ** & & $*$ & & $* * * *$ & & *** \\
\hline arved & 6 & $\begin{array}{ll}41 \cdot 3 & 0.7\end{array}$ & $36.6 \quad 0.6$ & $184 \cdot 3$ & $9 \cdot 9$ & $321 \cdot 9$ & $9 \cdot 5$ & 1319 & $20 \cdot 7$ & 12.9 \\
\hline efed & 5 & $73 \cdot 0 \quad 1 \cdot 9$ & $57 \cdot 0 \quad I \cdot 5$ & $294 \cdot 5$ & $5 \cdot 4$ & $469 \cdot 7$ & $21 \cdot 9$ & 5367 & $210 \cdot 2$ & $115.5 \quad I 1.5$ \\
\hline & & NS & NS & $\mathbf{N}$ & & & $S$ & * & & ** \\
\hline
\end{tabular}

NS, not significant.

${ }^{*} P<0.05,{ }^{* *} P<0.01,{ }^{* * * P}<0.001$. Statistical comparisons are made between starved and control groups, and between refed and control groups.

\section{MATERIALS AND METHODS}

Male, 25-day-old Sprague-Dawley rats (ARS, Madison, Wisconsin), weighing approximately $68 \mathrm{~g}$, were housed individually in wire bottom cages. Room lighting consisted of equal $\mathrm{I} 2 \mathrm{~h}$ periods of light and dark. Tap water was available ad lib. Four animals were killed by ether anaesthesia at the start of the experiment to serve as a baseline control. All food was withdrawn from six animals. These animals were killed after a $40 \%$ decrease in body-weight. A further five animals were also starved to a similar $40 \%$ loss in body-weight and then refed ad lib. a stock chow diet (Ralston Purina Food Co., St Louis, Missouri). These animals were killed when they returned to their original body-weight (approximately $70 \mathrm{~g})$.

All animals were allowed to enter rigor mortis at $20^{\circ}$. This occurred at $4-6 \mathrm{~h}$ post mortem. The gastrointestinal tract was removed, from the stomach to the rectum, and weighed. This weight, when subtracted from the body-weight, gives the empty-body-weight. The heart, kidney, liver and epididymal fat pads were dissected and weighed. Three skeletal muscles, the plantaris and soleus (hind-limb) and the biceps brachii (fore-limb) were dissected, freed of adhering fat and connective tissue, weighed, and placed in buffered neutral formalin (100 ml/1) for at least $10 \mathrm{~d}$. Errors in the measurement of the diameter or area of fibres are introduced if the muscles are placed in the fixative before rigor mortis (Levine \& Hegarty, 1977). Because of the excitability of muscle when taken as a biopsy sample, some fibres exhibit excessive stretching or contracture and must be excluded from a study (Hansen-Smith, et al 1979). For these reasons, all cellularity measurements were made on muscles that had entered rigor mortis. Muscle fibre number and diameter were determined simultaneously on a Coulter Counter (Coulter Electronics, Hiahleah, Florida) as described by Thompson et al. (1979).

\section{RESULTS AND DISCUSSION}

A $40 \%$ reduction in body-weight, induced by a total withdrawal of food for $3 \mathrm{~d}$, produced a significant decrease in the weight of the heart, kidney, liver and epididymal fat pads of young male rats (Table I). Protein-energy malnutrition in children also produces a decrease in the weight of the heart and kidneys (Alleyne et al. 1977). Recent evidence has indicated that a severe restriction of dietary protein during postweaning growth in rats produced a decrease in the weight of the epididymal fat pads (Tulp et al. 1979). Refeeding 
Table 2. Muscle weights (mg), and muscle fibre number and diameter ( $\mu \mathrm{m})$ in control, starved and refed rats

(Mean values with their standard errors

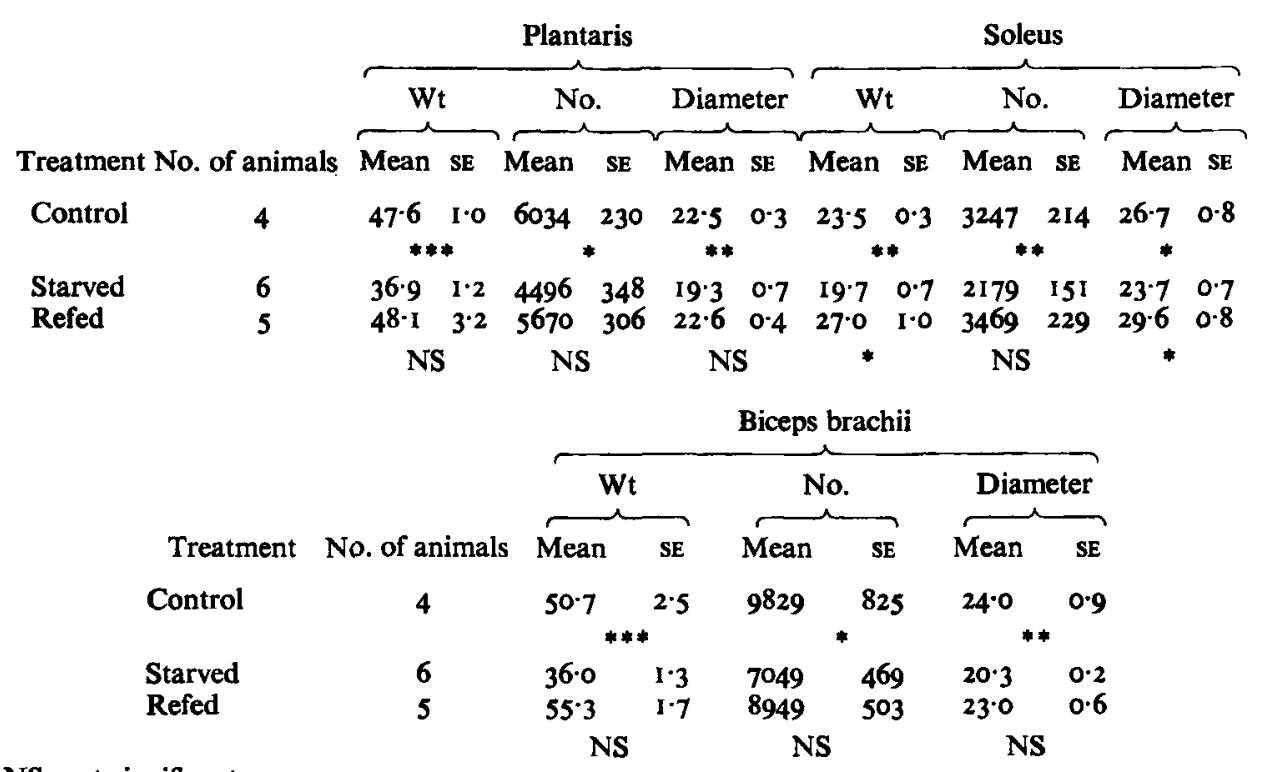

NS, not significant.

$* P<0.05, * * P<0.01,{ }^{* * *} P<0.001$. Statistical comparisons are made between starved and control groups, and between refed and control groups.

the starved animals to their original body-weight, which occurred after $2 \mathrm{~d}$ ad lib. feeding of a stock diet, returned the heart and the kidneys to their original weight, increased the weight of the liver $(P<0.05)$ and produced a deficit $(P<0.01)$ in the weight of the epididymal fat pads when compared to the control animals. Miller \& Wise (I976) concluded from their own work and that of other researchers that protein synthesis is a more energy-wasteful process than fat synthesis. Under the conditions of the present experiment it appears that the energy intake on refeeding has been diverted to the more energy-wasteful process of protein synthesis rather than to fat synthesis. This conclusion was deduced from the weights of the liver, heart, kidney and epdidiymal fat pads (Table I) and from the weights of the skeletal muscles (Table 2).

Prolonged total restriction of food caused a significant decrease in the weight of the three skeletal muscles studied (Table 2). However, the extent of this decrease differed, being least in the soleus and greatest in the biceps brachii. Refeeding the starved animals produced a return to the original weight in the plantaris and biceps brachii, and a significant increase $(P<0.05)$ when the weight of the refed soleus is compared to its weight in the control animals. Dickerson \& McAnulty (1975) reported that the growth pattern was not the same in each muscle during refeeding; this observation was confirmed in our experiments. When the muscle weights in Table 2 are expressed as a proportion of body-weight (Table $I$ ), the trends were similar for all three muscles; an increase during starvation and a return to control values when the animals are refed to the control body-weight. Dickerson \& McAnulty (1975) found that there was a tendency for muscles to maintain their correct weight relative to body-weight. The nutritional insult in their experiment involved maintaining weanling rats at their original body-weight by restricting dietary intake. Therefore, the more severe 
starvation used in the present experiment caused a greater effect on body composition, as seen in Table $\mathrm{I}$.

The reduction in muscle weight was produced by a decrease in both the number and diameter of muscle fibres. The decrease in muscle fibre diameter was expected because of similar reports when growth rate is reduced in undernourished children (Montgomery, 1962; Cheek et al. 1970), young rats (Hill et al. 1970) and pigs (Stickland et al. 1975) and when mice lost body-weight (Goldspink, 1965; Rowe, 1968). However, the decrease in the number of muscle fibres was unexpected because all of the previously mentioned studies, with the exception of Montgomery's ( 1962 ) work on children, indicated that a restricted food intake had no effect on muscle fibre number. Too rigid a comparison between studies may be misleading since different muscles were chosen in the various studies. The present work indicates, for example, that there is a variation in the response of different muscles to reduce food intake. Muscle fibre number values in the present study were confirmed by counting the total number of fibres in a complete cross-section of muscles. The appearance of the muscles in cross-sections or in electron micrographs (Layman, 1978) did not indicate any loss of muscle fibres. The question then remains as to how the muscle appears to 'lose' muscle fibres during prolonged starvation without any apparent evidence of the loss. An attempted answer might be provided by other work in this laboratory. A decrease in muscle fibre number was obtained during normal growth in four different skeletal muscles of the rat. It was speculated that fibre fusion occurred (Layman et al. 1980). A similar response may be occurring in the muscles studied in the present experiment. If this phenomenon does occur, then it is contrary to the observation that muscle fibre splitting occurs in muscle undergoing atrophy (Lancet, I978). What can be concluded with certainty is that the appearance under the light microscope of muscle from rats totally restricted from food for a prolonged period of time does not show the extensive damage observed in muscles from children with protein-energy malnutrition (PEM) (Montgomery, 1962). Refeeding the rats to their original body-weight returned any decreases in either the number or the diameter of muscle fibres or both (Table 2). The significant increase in the weight of the soleus when compared to the muscle from the control animals was due to a significant increase $(P<0.05)$ in muscle fibre diameter. Muscle fibres from the refed animals appeared normal under the light microscope. This was not unexpected in view of the excellent recovery of severely damaged muscle in nutritional muscular dystrophy (Chan \& Hegarty, I977). It seems, therefore, that skeletal muscle in the rat has a good capacity for recovery in a short time period from extensive weight loss due to undernutrition. This observation is in agreement with a statement made by Goldspink (1977) on the rapid recovery of skeletal muscle from the effects of immobilization "... skeletal muscle is not the slowly adapting tissue it was once believed to be'' Hansen-Smith et al. (I979) also reported a rapid response in muscle fibre size after initiation of nutritional rehabilitation programmes for children with PEM. However, neither their work, not that of Cheek et al. (1970) and Krishnamurthy et al. (I97I) could show a return to the normal fibre size in the clinically recovered children. In fact, Hansen-Smith et al. (1979) found that the fibre sizes of clinically recovered children were only approximately $60 \%$ of that for a well-nourished 6-month-old control child. These same authors claim that the question of fibre number remains unresolved in studies on muscles from children. They conclude that there is no strong qualitative morphological evidence for a substantial addition of new fibres during recovery. Evidence from our experiment indicates that decreases in the number and in the diameter of muscle fibres produced by prolonged starvation do return to normal values when the rats are refed to their original body-weight. It can be concluded that the recovered muscle probably possessed normal mechanical properties on the basis of evidence presented by McCarter et al. (1978). It is appropriate to end with a quotation from Widdowson (1976): 'We must be very careful in drawing con- 
clusions about the efficiency of an organ, either infant or aduit, from an analysis of the number of cells in it, without considering its size, structure and performance relative to the body from which it came.'

\section{REFERENCES}

Alleyne, G. A. O., Hay, R. W., Picou, D. I., Stanfield, J. P. \& Whitehead, R. G. (1977). Protein-Energy Malnutrition. London: Edward Arnold.

Chan, A. C. \& Hegarty, P. V. J. (1977). Br. J. Nutr. 38, 361.

Cheek, D. B., Hill, D. E., Cordano, A. \& Graham, G. G. (1970). Pediat. Res. 4 , 135.

Dickerson, J. W. T. \& McAnulty, P. A. (1975). Br. J. Nutr. 33, 171.

Goldspink, D. (1977). J. Physiol., Lond. 264, 283.

Goldspink, G. (1965). Am. J. Physiol. 209, 100.

Hansen-Smith, F. M., Picou, D. \& Golden, M. H. (1979). Br. J. Nutr. 4I, 275.

Hill, D. E., Holt, A. B., Parra, A. \& Cheek, D. B. (1970). Johns Hopkins Med. J. 127, 146.

Kim, K. O. \& Hegarty, P. V. J. (1978). Proc. Nutr. Soc. 37, 1 I4A.

Krishnamurthy, D. I., Kanan, S., Krishnamurthi, D. \& Chandra, H. (1971). Indian Pediat. 8, 814.

Lancet (1978). Lancet i, 646.

Layman, D. K. (1978). Biochemical and morphological changes in skeletal muscle fibers during normal growth and prolonged starvation. PhD Thesis, University of Minnesota.

Layman, D. K., Hegarty, P. V. J. \& Swan, P. B. (1980). J. Anat. 130, 159.

Levine, A. S. \& Hegarty, P. V. J. (1977). J. Anat. 123, 313.

McCarter, R., Yu, B. P. \& Radicke, D. (1978). Nutr. Rep. int. 17, 339.

Miller, D. S. \& Wise, A. (1976). Nutr. Metab. 20, 25.

Montgomery, R. D. (1962). J. clin. Path. 15, 5 II.

Rowe, R. W. D. (1968). J. Exp. Zool. 167, 353.

Sands, J., Dobbing, J. \& Gratrix, C. (1979). Lancet ii, 503.

Stickland, N. C., Widdowson, E. M. \& Goldspink, G. (1975). Br J. Nutr. 34, 421.

Thompson, E., Levine, A. S., Hegarty, P. V. J. \& Allen, C. E. (1979). J. Anim. Sci. 48, 328.

Tulp, O., Gambert, S. \& Horton, E. S. (1979). J. Lipid Res. 20, 47.

Widdowson, E. M. (1976). Proc. Nutr. Soc. 35, 357. 